\title{
EXPERIEnCe TeACHING CirCuit Courses to Civil EngINeERS
}

\author{
Michael Cooper-Stachowsky and Ayman El-Hag \\ University of Waterloo \\ ahalhaj@uwaterloo.ca
}

\begin{abstract}
At the University of Waterloo, students from many non-electrical engineering programs are required to take basic circuits courses. These courses are often disliked by students who do not see their relevance and cannot contextualize the material. In 2019 a new version of this course was developed to cater to the specific needs of civil engineering students. The new course was based around teaching civil engineers circuit theory through relevant examples and focusing on the content that civil engineers would reasonably be expected to see in the field. Lab exercises were developed to encourage independent capacity in circuit building and deep understanding of sensors and instrumentation. Student satisfaction with the course and performance on assessments has increased with the changes.
\end{abstract}

Keywords: electric circuits, civil engineering, sensors and instrumentation, teaching non-majors

\section{INTRODUCTION}

Students in different engineering disciplines are required to take courses outside their major to expand their engineering background. After graduation, students understand the importance of knowing about other engineering disciplines. However, it is hard for the students to see this connection during their undergraduate studies. Non-major courses are also sometimes offered in a similar way to those offered to major students, which makes it difficult for non-majors to connect to the course content. Furthermore, non-majors tend to take only one of these courses in their entire career, leading instructors to think they need to cover as much material as possible [1].

Instead, we should focus on a curriculum that fosters the intellectual skills that the student needs to succeed, as students who are non-majors may have less background in the course concepts and procedures [2].

There are several strategies that can be used to address issues facing non-majors. First, teachers must be interested in teaching the specific course to non-major students and communicate this interest genuinely [3]. Second, the instructor should be able (or learn) to "speak the students' language" and understand the connection between the course and the students' needs. This can help to remedy the problem of the students feeling disconnected from the material [4]. Third, there is a need to focus on experiential teaching to non-majors, letting them explore the topics from basic to complicated, rather than "from theory to practice" [5]. The list above is certainly not exhaustive, but those three principles formed the basis of our course redesign and so we have focused on them here.

In this paper, we will highlight our experience in introducing a classical circuit course to civil engineers. The course had previously been perceived very poorly by the students. We observed increased student performance and ownership over their own learning and excellence.

\section{HISTORY OF THE COURSE}

Prior to 2019, the same introductory linear circuits analysis course was taught to first year Civil, Environmental/Geological, Management, Chemical, and Mechanical engineering students at the University of Waterloo. This course, GENE123, was a comprehensive introduction to the theory of linear circuits from the perspective of electrical engineering. It consisted of a lecture component ( 3 lecture hours per week) as well as a hands-on laboratory (5 weeks of the term) and interactive, computer delivered tutorials (CDTs) for the remaining weeks of the term.

CDTs were timed quizzes marked automatically by computer, worth $1 \%$ of the final grade each. Students have unlimited access to the Internet and may discuss the questions with teaching assistants (TAs) and each other.

As the programs evolved it became clear that a single general course was insufficient to meet the needs of all students. Civil, Environmental/Geological, and the new Architectural engineering programs (hereafter referred to as "Civil Engineering", to reflect the department in which these programs are housed) were interested in modifying GENE123 to be more relevant for their students. Civil Engineering instructors noted that two components were lacking: 
1. Students in upper years lacked the basic circuit building skills that they needed to complete laboratory exercises, despite having gone through GENE123's laboratory component.

2. All subsequent interactions with circuits concepts revolved around sensors and instrumentation, which were covered only tangentially in GENE123.

In addition, observations of student performance during the lab/CDT sessions indicated that these sessions were not causing the desired learning to take place. Students were improving their circuit building and analysis skills but did not appear to be progressing towards mastery. Members of the teaching team felt that they were essentially guiding the students through the lab exercises without the students really understanding what they were doing and why it was relevant.

The authors redesigned the course content in both lectures and labs to address these issues.

\section{OVERALL COURSE REDESIGN}

\subsection{Original course structure}

As previously mentioned, GENE123 course was offered as a classical circuit course that covers:

1. DC circuit analysis: Different circuit analysis techniques are introduced,

2. AC circuit analysis: Similar to the DC analysis, the same techniques are taught but in the context of AC analysis where the source supplies AC voltage and current, and

3. Transient analysis: This part of the course covers the behaviour of a first order circuit when it is switched on or off.

The course content is very similar to a typical circuit course that is usually offered to electrical and computer engineering students.

\subsection{Changes to the Course Structure}

Redesigning the course was based on the following principles:

1. Minimize the circuit content by removing irrelevant material to civil engineering students. This includes removing topics like transient analysis. Also, minimize the number of circuit analysis techniques. Hence, topics like Mesh analysis and Thevenin equivalent circuits were also removed from the course.
2. Introduce different types of sensors that are related to civil engineers like strain gauges, load cells, LVDTs and thermocouples.

3. Concentrate on analyzing and addressing how circuit analysis techniques apply to instrumentation and measurement using circuits like the Wheatstone bridge, filters and amplifiers.

In general, the lecture content was broken into two main components:

1. Circuit tools ( $50 \%$ of the lecture content): covers the basic circuit analysis techniques that are necessary for the students to analyze instrumentation circuits.

2. Measurement and instrumentation $(50 \%$ of the course content): this part concentrates on the practical aspect of circuits to civil engineers.

\section{REDESIGN OF THE LABS}

\subsection{Original course structure}

The students would meet for 3 hours in the lab every week. Previously, this was split into CDTs and hands-on sessions on alternate weeks.

The teaching team observed that students were often ill prepared and unable to complete the CDT in the time given. The teaching team speculated that this was due to a combination of the difficulty of the problems, the relatively low weighting of each CDT, and other student commitments.

Labs consisted of a pre-lab exercise, due at the beginning of the lab session, and a series of hands-on exercises that allowed students to explore concepts learned in class. Students rarely linked what they did in the pre-lab to the lab activities, despite the pre-labs being designed as preparatory exercises to the activities. Quality of student reports were low, with frequent glaring errors. For example, students would often take incorrect measurements that were off by orders of magnitude but would not catch the error. Student ability to read and build a circuit diagram was low, as was their mastery of the equipment. As with CDTs, labs were not worth much towards the overall course grade (10\% total).

\subsection{General Changes}

The changes discussed in this section are not specific to Civil Engineering students and have since been implemented in other introductory circuits courses.

We decided to remove the CDTs entirely and to expand the number of lab activities. Hands-on activities would now take place every week. 
Pre-lab exercises were also removed. We incorporated them as in-lab "checkpoints" in the lab manuals, which were moved to an online platform. These checkpoints were delivered in two formats - either computer graded (as though they were CDT questions) or evaluated by the TAs. TA-evaluated exercises consisted of a brief inspection of the students' circuits with verbal feedback. The evaluations require students to demonstrate a working circuit or measurement technique. Students may re-check their circuit an unlimited number of times if they are incorrect.

Note that during the COVID-19 pandemic, students were expected to build real circuits using equipment purchased online. TA evaluations were not possible during the pandemic, but students were able to reach out for help via video chat and TAs were able to inspect circuits if needed. We ensured that a TA was available at least one hour per day for drop-in video help.

Students were given access to an online circuit simulator [6] and were expected to use it to simulate their circuit's behaviour before building it. This eliminated questions such as "what am I expecting to see?", because the students could verify the circuit's behaviour before building the circuit. The benefit of using a circuit simulator compared to hand calculations is that we were able to introduce much more complicated circuits earlier in the term, and to design the lab component to focus on skills acquisition more than theoretical concepts. The simulator also helped during the at-home labs of the pandemic, where students could simulate labs that they did not have all of the equipment for.

A much greater emphasis was placed on requiring the students to design, build, and debug their own circuits. Lab TAs were trained not to give students direct answers, instead teaching them general circuit building skills. For example, if a student were to ask a TA to verify whether their circuit was built correctly, the TA would spend time teaching the student how to verify that themselves using their circuit diagram and the simulator. The TA would never give a "yes" or "no" answer to such a question.

Students are required to design and communicate their own experiments for most labs. The lab manuals provide a set of specifications that their circuits must meet (such as "the current through the LED must not exceed 15mA"), and it is the students' responsibility to determine whether their circuit meets that requirement, and to provide sufficient evidence that it does.

\subsubsection{Methods of Feedback}

Due to the increased requirement of independent investigation, feedback in the labs is given early and often. It is crucial in the first weeks of the course that students can ask any question they want and to get verbal feedback in the labs. This verbal feedback follows the rule above, i.e. students are taught how to determine the answers for themselves, not given the answers directly.

Labs are now worth more of the total course grade, at $30 \%$. Lab reports are given detailed feedback by a dedicated marking TA, and lab reports are marked before the next lab session. Since lab reports follow a similar format each week, students can use their feedback from previous weeks immediately to improve their subsequent reports.

\section{RESULTS AND OBSERVATIONS}

Results of the change were observed in four places: student satisfaction with the course, student surveys, teaching team observation of student competence, and student grades.

Students are asked to evaluate their satisfaction with the course during the course critiques, and a score out of 100 is created for feedback to the instructor. Prior to the redesign, average student satisfaction was $71.3 \%$, with the lowest satisfaction levels around $20 \%$. Post-redesign average student satisfaction is $82 \%$ with all semesters' ratings above $80 \%$.

A second survey was run in which students were asked Likert questions about whether they learned each of the Intended Learning Outcomes (ILOs) of the course. Students responded on a 5-point scale, from "strongly disagree" to "strongly agree", with "neutral" in the middle. A majority of the 65 respondents selected either "agree" or "strongly agree" for four out of five ILOs.

At the end of the summer of 2019 semester, students were asked to tell us one thing that they felt they learned in this course. Student responses were aggregated by a teaching assistant who grouped them into categories. Of the 73 respondents, 54 (74\%) mentioned that they learned to build electric circuits. This is a key learning outcome of the course [7].

Graduate TAs were spoken to regarding their perceptions of student competence in circuit building and circuit analysis. Through interviews with a TA who taught both versions of the course, students in the new version were identified as being more competent and asking fewer questions related to basic content. The TA noted that students are not making as many of the mistakes that were made in the previous versions, and that they appeared to understand the equipment and the objectives of the lab exercises much more [8]. Student competence also clearly improves throughout the semester, as was noted by several members of the teaching team. 
Quantitatively, student performance is assessed through grades on both lab reports and exams. For lab grades, the expected trend is that they will increase throughout the semester as feedback is incorporated. This is indeed what is seen. Lab report grades show a clear trend towards mastery. Grades for report 2, offered early in the term, show a flat distribution, with approximately equal numbers of students getting below $60 \%(\mathrm{~N}=31)$ and above $90 \%(\mathrm{~N}$ $=35)$. Most students $(123 / 162)$ achieved a grade above $70 \%$. By lab 5, only 2 students earned grades below $60 \%$, while 159/162 earned grades above $70 \%$. Finally, students achieve a consistent average grade on the midterm and final of approximately $80 \%$.

The results in the above section are used in accordance with the University of Waterloo's Research Ethic's Board policies on secondary use of aggregate information.

\section{CONCLUSIONS}

The new version of the course has shown a clear trend towards improved student performance and satisfaction. Students identified that they achieved a majority of the ILOs and teaching team observations support this.

\section{REFERENCES}

[1] C. Hurney, "Learner-Centered Teaching in Nonmajors Introductory Biology: The Imapct of Giving Students Choices," Journal of Microbiology and Biology Education, vol. 13, no. 2, p. 1330141, 2012.

[2] T. Larkin-Hein, "New Methods for Teaching Introductory Physics to Non-Majors," in Annual conference of the American Society for Engineering Education, Saint Louis, 2000.

[3] W. Zilan, X. Pan and L. Jing, "How to Improving the noncomputer science students' computer ability (sic)," in International Conference on Computer Science and Education, Singapore, 2011.

[4] K. Fuller, "Beyond Reflection: Using ePortfolios for Formative Assessment to Improve Student Engagement in Non-Majors Introductory Science," The American Biology Teacher, vol. 79, no. 6, pp. 442-449, 2017.

[5] W. Peng, "Teaching Research and Thinking on the Computer Course of Non-computer Majors in Universities and Colleges (sic)," in International Conference on Educational and Information Technology, Chongqing, 2010.

[6] P. Falstad, "The Falstad Circuit Simulator," [Online]. Available: falstad.com/circuits/circuitjs.html. [Accessed 22 January 2020].

[7] A. Clark, "GENE123 Lab Creation Report," University of Waterloo, Waterloo, 2019.

[8] M. Sadeghianlemraski, Interviewee, Personal interview. [Interview]. 22 January 2020. 